\title{
LAS SOCIEDADES COLECTIVAS \\ Y COMANDITARIAS EN LA DINAMICA \\ EMPRESARIAL ESPAÑOLA DEL SIGLO XIX *
}

\author{
JOSE RAMON GARCIA LOPEZ \\ Universidad de Oviedo
}

La economía española a lo largo del siglo XIX, en su proceso de transformación hacia una configuración de tipo capitalista, tuvo entre sus notas definitorias la superposición o coexistencia de formas antiguas y modernas: lo que el profesor Sánchez-Albornoz designó como una economía dual ${ }^{1}$. Esta dualidad se manifestó también en las modalidades jurídicas de asociación mercantil, en las que predominaban las formas de tipo antiguo - las sociedades colectivas y comanditarias - mientras se abrían paso tardía y lentamente, con no pocos titubeos e incluso retrocesos, las formas más modernas, las sociedades de responsabilidad limitada, las sociedades anónimas ${ }^{2}$. El objeto de estas notas es analizar las causas que pudieron actuar como lógica económica para mantener este predominio, y al mismo tiempo evaluar los efectos que de ello se derivaron, habida cuenta de la influencia que las formas de asociación empresarial tienen sobre los procesos de crecimiento económico.

Está fuera de discusión el cúmulo de ventajas que para la empresa, y por tanto para el conjunto de los sectores productivos, supone el principio de responsabilidad limitada. Tanto por la limitación del riesgo como por la liquidez

* Presentada una primera versión en el I Seminario de Historia de la Empresa, Facultad de Ciencias Económicas de Granada, 1991. Agradezco los comentarios de los asistentes, así como las observaciones de los lectores-árbitro de la RHE, que he procurado recoger.

I Sánchez-Albornoz, N. (1968).

2 Jiménez Araya, T. (1974), muestra cómo las sociedades anónimas fueron hasta comienzos del siglo $\mathrm{xx}$ las de menor importancia numérica, lo que, a su juicio, «confirma la tardia generalización de las formas capitalistas de gestión empresarial en la economía española», y Tafunell, J. (1989), p. 467, profundiza en la cuestión afirmando que «ni siquiera en el capital asociado hay una superioridad cierta de la forma de asociación anónima con anterioridad a la I Guerra Mundial», dado que en las sociedades anónimas el desembolso del capital no solia exceder del 25 por ciento del nominal fundacional. 
de las participaciones sociales y la posibilidad de captación de grandes sumas, la sociedad anónima representa el pilar fundamental del desarrollo capitalista. Ahora bien, es sabido que a pesar de ser conocida desde el siglo xvI, su arraigo fue lento en todos los países, y desde luego en España. ¿Cuáles pudieron ser las razones de este retardo en nuestro pais?

En nuestra opinión, varios factores contribuyeron a determinar, además de la inercia tradicional, la proliferación en el entorno español de sociedades colectivas y comanditarias en detrimento de las sociedades anónimas, y proponemos clasificarlos en dos grupos: los negativos, entre los que se encuentran las restricciones legales y la escasez de capitales; y los positivos, constituidos por las propias cualidades de las sociedades personalistas, por su funcionalidad y adaptabilidad a las condiciones de la época. Unos y otros conducirían a que los empresarios españoles del siglo XIX se decantaran de forma mayoritaria por aquellas formas juridicas. Analicémoslos.

\section{OBSTACULOS A LA FORMACION Y DIFUSION DE LAS SOCIEDADES ANONIMAS}

\section{Restricciones y prohibiciones legales}

El Código de Comercio de 1829, primera norma importante de legislación económica del siglo, vino a establecer unos criterios relativamente flexibles y permisivos, exigiendo para la constitución de sociedades anónimas simplemente la aprobación del Tribunal de Comercio (art. 293), debiendo ser sometidas a la «Soberana aprobación» sólo las que fuesen a disfrutar de algún privilegio real (art. 294). Las restricciones para las sociedades de responsabilidad limitada comenzaron a establecerse en 1847, y con notable dureza, cuando la Real Orden de 9 de febrero «creó un estado violento e insostenible, arrancando de los tribunales de Comercio la facultad de aprobación de los pactos sociales», disposición con la que se pretendia corregir el «lamentable descrédito» en que incurrieron estas compañias "por el abuso que se hizo de ellas en 1846, en que el público atónito presenció los mayores escándalos y los más punibles desafueros» ' 3 La citada Real Orden fue complementada por el Real Decreto de 15 de abril del mismo año, reconociéndose en ambos la necesidad de una ley que fijase de una manera permanente la organización de las compañias mercantiles

3 Tomado de la introducción a la ley de 1848 , recogida en la tercera edición del Código de Comercio, de Pedro Gómez de la Serna y José Reus Garcia, Madrid, 1959, p. 448. 
por acciones, ley que sería promulgada pocos meses después, el 28 de enero de 1848 , estableciendo en su artículo primero que «no se podrá constituir ninguna compañia mercantil, cuyo capital, en todo o en parte, se divida en acciones, sino en virtud de una Ley o un Real Decreto» 4.

Entre 1848 y 1868, año este último en que por Decreto de 28 de octubre fueron derogados la ley y reglamento de sociedades anónimas, se produjeron varias disposiciones que suavizaron las condiciones para la fundación de algunas sociedades anónimas según su objeto (leyes de Ferrocarriles de 1855, de Sociedades de Crédito y Bancos de Emisión de 1856 y de Minas de 1859). El profesor Tortella las ha estudiado en un trabajo ya clásico en el que considera que esta facilidad «constituia un sistema de discriminación en favor de la construcción ferroviaria, la minería, la banca y la finanza, en detrimento de la industria manufacturera» al hacer gravitar hacia estos sectores el capital líquido disponible '. La ley de sociedades de 19 de octubre de 1869 proclamó la libertad de asociación que estaría vigente el resto del siglo, sin más exigencia que la inscripción en el Registro de Comercio, primero, y en el Registro Mercantil, desde 1886.

Acotamos, pues, un período de veintiún años, 1847-1868, en el que la legislación obstaculizó, e incluso impidió, con las excepciones señaladas, la constitución de sociedades de responsabilidad limitada, pero una vez que la prohibición se levantó, no aumentó el número de sociedades anónimas creadas, que siguió siendo bajísimo durante las décadas siguientes (salvo breves repuntes de fiebre especulativa, como la de 1881-82 en Barcelona), lo que indica que no puede ser achacado a la legislación, más que para el período 1847-1868, el papel de obstáculo determinante, obligándonos a seguir indagando en otras motivaciones. Los efectos de la legislación sin duda fueron importantes, pero no explican por sí solos el predominio de las formas personalistas a lo largo del siglo.

\section{Dificultades para la disponibilidad de capitales}

Uno de los requisitos esenciales para romper el círculo vicioso del atraso e iniciar un proceso de desarrollo económico es la disponibilidad de capitales,

${ }^{4}$ Mayor flexibilidad se introduciria años más tarde (R.O. de 19 de octubre de 1853) para la isla de Cuba, que sólo obligaba a la Real aprobación a las compañias cuyo objeto fuese establecer bancos de emisión, construir carreteras, canales o ferrocarriles, y las que pretendiesen un privilegio exclusivo, quedando el Gobierno de la isla facultado para autorizar todos los demás tipos.

5 Tortella Casares, G. (1968), pp. 76-80. 
cuestión que en la España del siglo XIX presentaba graves carencias. Las deficiencias de los sectores productivos, con su parquedad en la generación de rentas, hicieron que el ochocientos español tuviese como una de sus características más visibles la penuria de ahorros y capitales. En esta situación, resulta explicable que las sociedades anónimas, por definición receptoras de grandes sumas, no tuviesen un campo favorable para su implantación. Sí lo tuvieron las de algunas ramas (ferrocarriles, banca, minería), cuando entre 1855 y 1865 llegaron capitales extranjeros en una cierta abundancia, y en algunos otros momentos muy concretos ${ }^{6}$, pero su presencia fue temporal y espacialmente limitada, quedando al margen la casi totalidad del entramado productivo.

Desde el punto de vista de la financiación, la mayor ventaja de las sociedades anónimas es que permiten a sus promotores manejar un capital mucho mayor del que ellos comprometen en el proyecto empresarial. Pero ello exige la existencia de un colectivo de inversores suficientemente numeroso para que, mediante pequeñas aportaciones, completen los crecidos capitales con que esas sociedades se constituyen, y esto no sucedió con carácter general en España hasta la última década del siglo xIx. Por eso, hasta entonces, no es difícil observar que, en algunos casos, las sociedades anónimas lo eran sólo relativamente, en el sentido de que sus socios eran perfectamente conocidos por constituir número muy reducido. No parece arriesgado afirmar, por tanto, que para los empresarios resultaba más sencillo acudir a la captación de unas pocas personas acaudaladas - los indianos cumplieron esta función de manera destacada - utilizando para ello formas jurídicas de asociación que les permitieran resolver con agilidad los problemas de constitución o transformación, y estas formas fueron las sociedades personalistas, especialmente las comanditarias ? En cuanto al funcionamiento posterior, resolvieron sus necesidades recurriendo a las instituciones bancarias (en su mayor parte también sociedades personalistas) para la financiación del circulante, lo que les permitía la autofinancia-

6 Por ejemplo, en los meses de fuerte especulación de la febre d'or barcelonesa, o, como pone de relieve Tafunell, J. (1989), p. 471, en los valores industriales bilbainos en la última década del siglo.

7 Hasta la última década de siglo las formas personalistas se observan en todos los sectores, incluso en las ramas industriales que requieren fuertes inversiones -empresas siderürgicas, navieras, quimicas, refinerías ...- que se constituian con las aportaciones de un reducido número de socios, que a veces tenian que buscar ayuda en otras regiones. En un trabajo en curso de realización sobre las constituciones de empresas en Asturias, realizado con el vaciado de protocolos notariales y del Registro Mercantil, hemos podido comprobar estos extremos; más aún, incluso una de las sociedades anónimas que son excepción, el Banco de Oviedo, se intentó constituir en 1863 con el concurso de los mayores comerciantes ovetenses, cuyo capital de un millón de reales, al ser considerado exiguo por el Gobierno, obligó a la ampliación, teniendo que acudir para ello a casas de fuera de la provincia para incrementarlo (García López, J. R., 1989, pp. 32-36). 
ción del capital fijo por reinversión de los beneficios, solución común a la adoptada por otros países en similares estadios de desarrollo ${ }^{8}$.

\section{PROPIEDADES DE LAS SOCIEDADES PERSONALISTAS QUE FAVORECIERON SU DIFUSION}

Si en páginas anteriores hemos considerado los factores que obstaculizaron el desarrollo de sociedades mercantiles de responsabilidad limitada, veamos ahora las razones que por propios méritos de las sociedades colectivas y comanditarias ayudan a explicar su arraigo en el siglo XIX español, y que, en parte, son fruto, contradictoriamente, de sus propias limitaciones.

\section{Facilidades legales para la constitución y modificación}

En primer lugar hay que destacar la extrema sencillez para llevar a cabo su constitución. Tanto en el Código de Comercio de 1829 como en el de 1885, el único requisito para su constitución era la realización de una escritura pública, que tenia que ser inscrita en el Registro General de Comercio de la provincia (desde 1886 en el Registro Mercantil). Todas las demás cláusulas, como número de socios, aportaciones, capital, duración, objeto, funcionamiento interno, etc., podian ser estipuladas libremente por los socios constituyentes con la sola exigencia de su inclusión en la escritura social. Idéntica facilidad había para reformar, ampliar, prorrogar o disolver el contrato de sociedad, y no era pequeña ventaja esta posibilidad de modificar el proyecto empresarial, que permitia adaptarse de modo inmediato a cualquier tipo de alteración en los planes de funcionamiento. No sólo por la posibilidad de incorporación o baja de socios, sino por cambio de objeto, duración y demás aspectos que definen una empresa.

\section{Mecanismos para la captación de capital}

El capital de las sociedades personalistas está formado por las aportaciones de los socios, pudiendo ser de distinta cuantía -e incluso puede haber algu-

8 Asi lo afirman Cameron, R. E. (1974, p. 69), y Bouvier, J. (1981, p. 146), y asi lo hemos comprobado en el entorno asturiano (Garcia López, J. R., 1988, pp. 149-153). 
nos socios que no participen del capital, los socios industriales-, y puede ampliarse por nuevas aportaciones o por la incorporación de nuevos partícipes, sin más requisito que modificar la escritura fundacional. La modalidad «en comandita», al permitir la incorporación de socios capitalistas, con la responsabilidad limitada a la suma aportada, solía ser la vía para ampliar el capital en la medida necesaria, sin apenas modificación, y sin que los nuevos socios comanditarios interfiriesen la gestión de la sociedad, ya que éstos tenian expresamente prohibido participar en la administración de la compañia. Esto aseguraba la continuidad del proyecto empresarial, que de este modo resultaba potenciado sin merma del control ejercido por los socios colectivos. Por otra parte, a los comanditarios se ofrecia la posibilidad de valorizar su capital, invirtiendo sus fondos en una actividad productiva sin ser empresarios ni comprometerse en la gestión, de lo que obtenían por lo general una remuneración fija más una participación en los beneficios de la firma. La compañia comanditaria por acciones, al permitir participaciones transmisibles, iba más allá, aproximándose a las condiciones de las sociedades anónimas, añadiendo además una posibilidad de participación indirecta de los comanditarios, si no en la administración, sí de control a través de la Comisión Consultiva.

\section{Flexibilidad de funcionamiento y adaptabilidad}

La atención directa de los negocios por sus propietarios no tiene por qué garantizar el éxito, pero, sin embargo, hay que reconocer que en la España del siglo XIX no existía un grado de capacitación profesional suficientemente desarrollado como para facilitar los cuadros técnicos capaces de llevarla a cabo, de modo que la cualificación se adquiria, prácticamente de forma exclusiva, a través de la experiencia en los negocios. De este modo, la figura de socio y de gestor se confundian, y, de hecho, la existencia de socios industriales no era otra cosa que una forma de otorgar el status de socio al que no disponiendo de capital sólo aportaba su industria, es decir, sus conocimientos y dedicación. Los socios industriales eran remunerados con una parte de los beneficios, que, por lo general, no retiraban del negocio y terminaban añadiendo al capital. Similar tratamiento tenian algunos empleados que, en función de su dedicación o aptitud, pasaban a participar de los beneficios - se solia dedicar para estos fines entre el 10 y el 20 por ciento de los resultados- y que solía ser la vía para su conversión en socios de pleno derecho. Este mecanismo de integración progresiva y participación en el capital de la empresa funcionó de manera general en España (y en mayor medida, si cabe, en las colonias de ultramar) como lo 
habia hecho en otros paises en circunstancias similares. Y no sólo en el comercio, sino también en empresas industriales. Son conocidas las biografías de muchos empresarios y financieros (tanto españoles como indianos) que de este modo pudieron hacerse con los conocimientos y el capital necesarios para iniciar su carrera empresarial, que de otro modo les hubiera resultado totalmente inalcanzable.

En cuanto al funcionamiento, la estructura organizativa de las sociedades personalistas era extremadamente ágil y contrastaba con la más pesada de las sociedades anónimas, con diversos órganos de gobierno o control (Juntas de accionistas, Consejos de administración, Comisarios Regios...) que llevaban aparejado un costo nada despreciable y que no añadía ventajas funcionales ${ }^{9}$. Por lo que se refiere a la adaptabilidad, en otro lugar nos hemos ocupado de un sector concreto, el bancario, en el que fueron abundantes los ejemplos de superación de las fuertes crisis -especialmente la de 1865-66 - por parte de las sociedades personalistas, mientras sucumbían buena parte de las sociedades anónimas; no porque las pérdidas fuesen menores en aquéllas, sino porque la responsabilidad personal obligaba a aplicar una estricta y acertada política de saneamiento ${ }^{10}$.

Se achaca como fuerte inconveniente de las sociedades personalistas la limitación a la vida de los socios, pero en la práctica esto no cercenaba la duración de la empresa, sino, en todo caso, de la razón social. Fallecido o retirado uno de los socios, o bien la razón social figuraba durante un tiempo con el

${ }^{9}$ Un ejemplo ilustrativo de cambio de sociedad anónima a sociedad personalista es el de la Sociedad Española Mercantil e Industrial, que pasó a girar como «Weisweiller y Bauer», puesto que, como afirma el profesor Tortella, «no habia ya razón para mantener una entidad del tamaño de la Sociedad Española, con todos los inconvenientes de las sociedades anónimas (el subrayado es mio), cuando Weisweiller y Bauer podian realizar tanto o más sin verse estorbados por juntas de accionistas y sesiones del Consejow (Tortella Casares, G., 1973, p. 291). Por otra parte, los comisarios regios bancarios fueron objeto de permanentes protestas, hasta que tuvieron que ser suprimidos (Garcia López, J. R., 1989a, pp. 37, 74-78).

${ }^{10}$ Garcia López, J. R. (1989b), pp. 129.130, compara los efectos de la crisis de 1864-65 sobre un banco (Banco de Oviedo) y una casa de banca (Enrique Säinz, de Madrid); en ambos casos el impacto fue brutal, pero difirieron en el modo de superarlo. Naturalmente, también las casas de banca quebraban, pero el respaldo patrimonial suponia una cierta garantía para los acreedores; por ejemplo, una de las quiebras bancarias más sonadas, la de la casa de banca de Enrique O'Shea y Compañia, de Madrid, declarada en 1865, tras haber suspendido pagos en 1862, se resolvió liquidando a sus acreedores el 76 por ciento de la deuda (Archivo Histórico del Banco de España, Secretaría, Leg. 2076). Esta politica empresarial no fue exclusiva de la rama bancaria, como lo demuestra un caso relevante estudiado por J. Nadal y E. Ribas para dos empresas textiles, la fábrica «de la Rambla» (sociedad colectiva) y «La España Industrial» (sociedad anónima), que observaron politicas de ampliación de beneficios radicalmente distintas, realizando la primera prudentes amortizaciones, mientras la segunda comprometía su futuro con una irresponsable politica de reparto de dividendos (Nadal Oller, J., y Ribas, E. (1974), pp. 72-78). 
añadido «en liquidación» (que nada tenía que ver, como a veces se cree, con la suspensión de actividades) hasta que se formalizase la nueva, o de forma inmediata se alteraba con la incorporación, en su caso, de los apellidos de los nuevos socios gerentes. Estas reconstituciones aseguraban la continuidad del proyecto empresarial, adaptándose a las nuevas circunstancias. Todavía se puede añadir que, precisamente por la corta vida laboral de los socios (especialmente corta en el ámbito colonial), esa flexibilidad, al permitir la retirada no traumática y la incorporación natural de los nuevos socios, aseguraba los relevos que garantizaban la continuidad, constituyendo un medio nada despreciable de generación de empresarios.

\section{CONCLUSION: EFECTOS POSITIVOS DE LA DIFUSION DE LAS SOCIEDADES PERSONALISTAS}

Sin duda lo deseable para que la economia española del siglo XIX hubiera conseguido mayores tasas de crecimiento habría sido el predominio de empresas con forma de sociedad anónima y elevados capitales que, como dice el profesor Tortella a propósito de la siderurgia, «hubieran aumentado la capacidad y la escala de las fábricas, y la producción hubiera crecido a ritmo mucho más rápido del que lo hizo» ${ }^{11}$, pero por las razones ya citadas no pudo ser así, y admitido esto, debemos preguntarnos si el mantenimiento de las formas personalistas de asociación fue una opción regresiva, o si, por el contrario, contribuyó a facilitar el desenvolvimiento económico. Ciertamente, es una obviedad que en ausencia de formas nuevas, la única opción era continuar con las conocidas, pero lo que pretendemos aquí es constatar que el desarrollo de los mecanismos de estas sociedades aportó notables beneficios sobre la dinámica empresarial.

En primer lugar debemos destacar que las posibilidades de integración en el negocio, a través de la participación en los beneficios primero y en la incorporación como socios después, actuó sobre los empleados como un poderoso estímulo al incremento de la dedicación y el rendimiento, lo que se traducia en una mayor eficiencia y, por tanto, en una mayor productividad. Pero, además, los beneficios repartidos entre los empleados suponian un medio de acumulación para ellos (fundamental, habida cuenta de las limitaciones de la época) y de autofinanciación para la empresa (no solian ser retirados, permaneciendo en forma de depósito para luego, en su caso, ser incorporados al capital).

11 Tortella Casares, G. (1973), p. 237. 
En segundo lugar, ya fuese por medio de la figura de socio industrial o por la vía de integración progresiva de empleados, estas sociedades ejercieron una indiscutible función de formación de empresarios, estableciendo un puente de unión del trabajo con el capital. Esta promoción era, además, fuertemente selectiva, y en la selección operaban fundamentalmente factores de eficacia y profesionalidad, ya que el interés de los socios era captar copartícipes eficientes, tanto para la marcha inmediata de la empresa como para su desenvolvimiento futuro, dado que, con frecuencia, la retirada de los socios consistía en pasar a la situación de comanditarios y, por tanto, su capital debería quedar en manos de buenos gestores.

La mayor objeción que se hace a las sociedades personalistas es la limitación de la cifra de capital, que le impide acceder a grandes proyectos o conseguir economías de escala. Sin negarlo, debemos matizarlo con la consideración de que estas formas sociales estuvieron presentes en todos los países en las primeras etapas de la industrialización, en los que el reducido tamaño de mercado y la ausencia de acumulación previa fueron determinantes a la hora de configurar el dimensionamiento empresarial.

En definitiva, cabe concluir que las sociedades colectivas y comanditarias fueron coherentes con la situación general de la economía española, que actuaron como factor dinamizador en un pais y una época con abundantes carencias y que permitieron que las diferentes ramas industriales y comerciales en las que fueron adoptadas experimentasen un notable crecimiento. Probablemente en ese contexto resultaban más anacrónicas, por demasiado avanzadas, las sociedades anónimas.

\section{BIBLIOGRAFIA}

BOUviER, Jean (1981): «Sistemas bancarios y empresas industriales en el crecimiento europeo del siglo XIX», en Vilar, P., y otros, La industrialización europea, Ed. Crítica, Barcelona, pp. 135-172

CAMERON, Rondeo E. (1974): La banca en las primeras etapas de la industrialización, Ed. Tecnos, Madrid.

GARCIA LOPEZ, José Ramón (1988): «Las relaciones banca-industria en el siglo XIX. Los banqueros y comerciantes banqueros en la industrialización asturiana», en Fernández de Pinedo, E., y Hernández Marco, J. L. (eds.), La industrialización del Norte de España, Ed. Crítica, Barcelona, 1988, pp. 147-153.

- (1989a): El Banco de Oviedo, 1864-1874. Historia económica de un banco de emisión, Ed. Mases, Gijón.

- (1989b): «El sistema bancario español del siglo xix: ¿una estructura dural? Nue- 
vos planteamientos y nuevas propuestas». Revista de Historia Económica, año VII-1, pp. 111-132.

JimEnEZ ARAYA, Tomás (1974): «Formación de capital y fluctuaciones económicas. Materiales para el estudio de un indicador: creación de Sociedades mercantiles en España entre 1886 y 1970", Hacienda Pública Española, número 27, pp. 137-185.

NADAL Oller, Jordi, y Ribas, Enric (1974): «Una empresa cotonera catalana: La fábrica "de la Rambla", de Vilanova, 1841-1861», Recerques, núm. 3, pp. 47-81.

SÁNCHEz-AlBornoz, Nicolás (1968): España bace un siglo: una economía dual, Ed. Península, Barcelona.

TAfunEll, Javier (1989): «Asociación mercantil y Bolsa», en Carreras, A. (coord.), Estadísticas bistóricas de España, siglos XIX $y \mathrm{XX}$, Fundación Banco Exterior, Madrid, pp. 463-483.

Tortella Casares, Gabriel (1968): «El principio de responsabilidad limitada y el desa. rrollo industrial de España: 1829-1869", Moneda y Crédito, número 104, pp. 69-84.

(1973): Los orígenes del capitalismo en España, Ed. Tecnos, Madrid. 